\title{
Stroke Care in Pakistan
}

\author{
Anjum Farooq ${ }^{\mathrm{a}}$ Narayanaswamy Venketasubramanian $^{\mathrm{b}} \quad$ Mohammad Wasayc $^{\mathrm{c}}$ \\ ${ }^{a}$ Department of Neurology, Bolan University of Medical and Health Sciences, Quetta, Pakistan and President

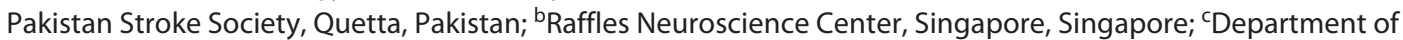 \\ Medicine, Aga Khan University, Karachi, Pakistan
}

\section{Keywords}

Stroke $\cdot$ Care $\cdot$ Awareness $\cdot$ Asia $\cdot$ Pakistan

\begin{abstract}
Increasing incidence of stroke and lack of infrastructure in both urban and rural areas needs immediate attention in Pakistan. There is a high proportion of young stroke with poor stroke outcomes. Acute stroke care is scarce in Pakistan due to the small number of neurologists ( 1 neurologist per 1 million population), few stroke units, and limited availability of alteplase (recombinant tissue plasminogen activator) in the country.

(C) 2021 The Author(s)

Published by S. Karger AG, Basel
\end{abstract}

\section{Stroke Burden in Pakistan}

Pakistan ranks number 5 in the world by population. The estimated population of Pakistan is 225 million with a median age of 22.5 years (https://www.worldometers. info/world-population/pakistan-population). There are no large-scale epidemiological studies available to determine the true incidence of stroke in Pakistan [1-3]. The estimated annual incidence of stroke in Pakistan is 250/100,000 [4]. A cross-sectional integrated population health survey was conducted on population aging $\geq 18$ years at 24 districts of Khyber Pukhtoonkhwa (one of the 4 provinces in Pakistan). Out of 22,500 participants of the study, 11,556 (51.4\%) were females and 10,944 (48.6\%) were males. The mean age of the study participants was $42 \pm 12.6$ years. About $66.4 \%(n=14,942)$ of the study population was $<50$ years of age. The majority $(74.66 \%)$ were from rural areas and about $10.9 \%$ had no formal education. Stroke was identified in 271 cases, and the prevalence of stroke was $1.2 \%$ [5]. Another published stroke prevalence study from Pakistan, conducted on adult Pushtoon community residing in Karachi, reports a $4.8 \%$ prevalence of stroke in that community with a similar ratio in men and women, and $30 \%$ of all strokes were reported to have occurred at the age of 45 years or less suggesting a high burden of young strokes in Pakistan [6, 7]. Ali and colleagues reported that the mean population age of patients with stroke in developing countries like Pakistan is a decade or younger than that of their Western counterparts [8]. Stroke risk factors in Pakistan are as high as in other countries in South Asia [8]. Stroke-related mortality has been reported in the range of $11-30 \%$ in Pakistan [8]. Age $>60$ years, severe hypertension, hyperglycemia, and unconsciousness are found to be poor prognostic factors [7].
C 2021 The Author(s).

Published by S. Karger AG, Basel

This is an Open Access article licensed under the Creative Common Attribution-NonCommercial-4.0 International License (CC BY-NC) (http://www.karger.com/Services/OpenAccessLicense), applicable to the online version of the article only. Usage and distribution for commercial purposes requires written permission.
Correspondence to:

Mohammad Wasay, mohammad.wasay@aku.edu 


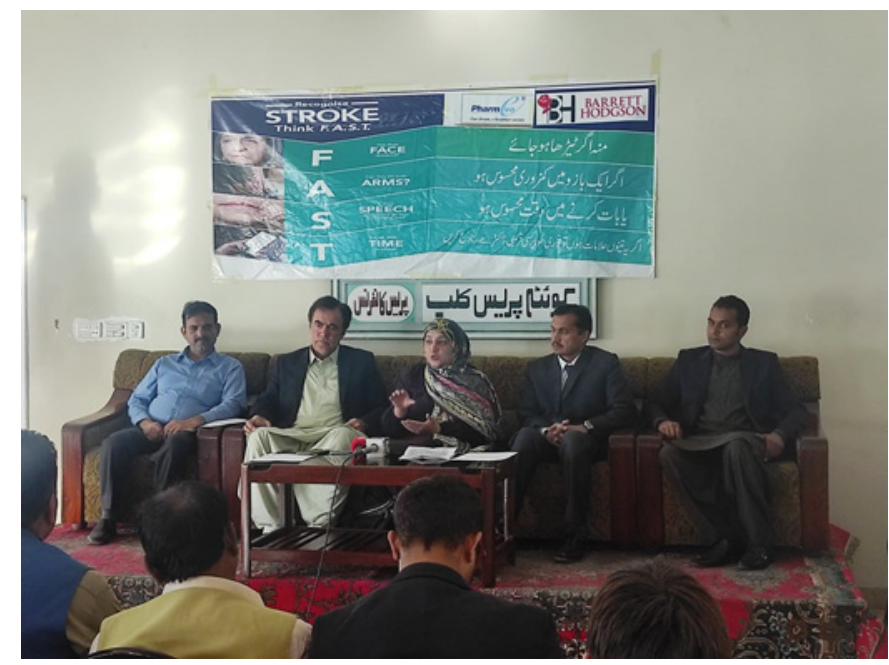

Fig. 1. Press conference regarding World Stroke Day at the Quetta Press Club.

\section{Current Stroke Care Facilities in Pakistan}

In Pakistan, approximately 10 stroke units have been established in different cities, but only 6 centers are offering intravenous thrombolysis (recombinant tissue plasminogen activator, $r$-tPA). Cost of care in the stroke unit is the single most important determinant in patients' ability to access acute stroke care at a private, tertiary care hospital in Pakistan [9]. Due to severe budget constraints, public health facilities are not capable of providing specialized stroke unit care in Pakistan. There is poor infrastructure for referring patients with symptoms of acute stroke to the centers which have a stroke neurologist and facilities to manage acute stroke and offer intravenous thrombolysis. At a tertiary care hospital in Pakistan, while immediate CT scan and stroke identification is the rule, the sophisticated stroke code system of calculating time for administering alteplase (r-tPA) in the form of door to CT time (target $<25 \mathrm{~min}$ ), CT to needle time (target $<20$ $30 \mathrm{~min}$ ), and door to needle time (target $40-60 \mathrm{~min}$ ) is not existent [10]. The number of stroke patients receiving alteplase ( $\mathrm{r}$-tPA) in Pakistan is extremely low because of prehospital delay, financial constraints, lack of tPA availability, and poor infrastructure [11]. Ather et al. [12] conducted a study in a single tertiary care hospital to determine the frequency of acute stroke patients reaching the hospital within the tPA (alteplase) window. Among 217 patients presenting to the hospital with acute ischemic stroke, only 16 were presented within $4.5 \mathrm{~h}$. Only $80 \mathrm{CT}$ scanners and 19 MRI machine are available throughout Pakistan mainly in large main cities [13]. Mechanical

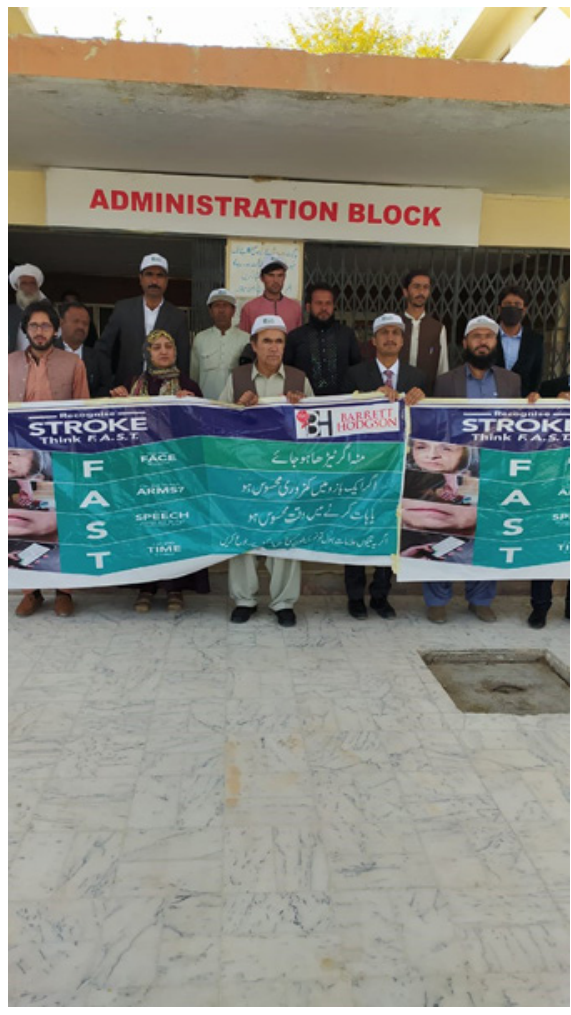

Fig. 2. Stroke awareness walk at the Bolan Medical Center.

thrombectomy is available at only 4 hospitals in the country with only 1 public hospital in Lahore offering mechanical thrombectomy in acute stroke [11]. One public teaching hospital is offering fellowship in neurointervention and mechanical thrombectomy [11]. Only 1 center in the country is offering 1-year stroke fellowship program training since 2009 [14]. The estimated number of trained rehabilitation medicine physicians in the country is 80 [15]. There are no neurophysicians in rural and small cities of Pakistan, and patients with acute stroke are treated by general physicians in the district hospital.

\section{Role of the Pakistan Stroke Society for Improving Stroke Care in Pakistan}

The Pakistan Stroke Society (PSS) was established in 2001, and it is affiliated with the World Stroke Organization and the Asia Pacific Organization. Its primary aim is to optimize stroke care in Pakistan. For this purpose, the Pakistan Stroke Society has taken several steps. These steps include organizing stroke workshops and collaborating with different societies to work for improving 
stroke care in the country. Stroke workshops organized by the Pakistan Stroke Society (PSS) put emphasis upon importance of stroke unit, intravenous thrombolysis, managing acute stroke patients, preventing recurrence of stroke, and stroke nursing care targeting the neurologist, general practitioners, nursing staff, and other paramedical staff. World Stroke Day is celebrated by the Pakistan Stroke Society (PSS) every year to spread knowledge and awareness of stroke through media and public awareness activities. In 2020, the PSS organized many activities in 15 cities of Pakistan on World Stroke Day. These included stroke awareness sessions for patients and general public and sessions for nurses to recognize stroke symptoms and stroke nursing care. On World Stroke Day 2020, press conferences were held in almost all big cities on the same day to highlight the importance of recognizing stroke as an emergency on national level which will help to get government attention to take important steps for improving stroke care in Pakistan (Fig. 1, 2). The PSS in collaboration with Angels Initiatives is working to improve stroke unit care especially intravenous thrombolysis and postthrombolytic care. With the immense effort of the PSS, alteplase (r-tPA) was recently registered in Pakistan. The PSS has signed a Memorandum of Understanding (MOU) with the Neuroradiology Society of Pakistan. Two societies will organize workshops on mechanical thrombectomy in 6 large cities in Pakistan. In the era of COVID-19, telestroke and teleneurology has gained popularity in Pakistan, but this is limited only to the teleclinics. Telestroke networks will be encouraged to contribute to knowledge by offering patients the opportunity to participate in clinical trials. National stroke guidelines were first published by the Pakistan Stroke Society in the year of 2010 [16]. Now, the PSS is working on updating national stroke guidelines which will be published by the end of the year 2021. Updated guidelines will emphasize on acute thrombolysis, developing stroke units throughout country, and secondary prophylaxis of stroke in Pakistan.

\section{Stroke Research in Pakistan}

The Pakistan stroke registry is the first national stroke registry for stroke patients in Pakistan. The duration of the study is 2019-2022, and its target is to enroll 5,000 patients with the diagnosis of acute stroke. This study will identify the stroke risk factors, stroke type, subtype, and stroke outcome. More than 70 centers throughout the country are participating in this study, and this will be the first-ever registry of this nature to determine the stroke epidemiology in Pakistan. The Stroke Research Network was established and trained with a grant from the George Institute. More than 10 stroke care physicians were trained for good clinical practice, research ethics, and stroke trial management.

\section{Conclusion}

Stroke burden is very high in Pakistan with very limited available current facilities for stroke care in the country. After the availability of alteplase (r-tPA) in Pakistan, immense effort is needed to improve stroke care and acute stroke centers. The Pakistan Stroke Society (PSS) is performing a leading role by arranging stroke workshops, sessions for public awareness, and stroke research including the first-ever national stroke registry. Our main objective in the coming years is to establish more stroke units and improve them to receive and manage stroke patients with intravenous thrombolysis.

\section{Statement of Ethics}

Figures were provided by the Pakistan Stroke Society. The Pakistan Stroke Society provided written permission to publish the figures.

\section{Conflict of Interest Statement}

The authors have no conflicts of interest to declare.

\section{Funding Sources}

No funding was received for the current study.

\section{Author Contributions}

Anjum Farooq contributed to data collection, data analysis, manuscript writing, and manuscript review. Narayanaswamy Venketasubramanian contributed to data analysis, manuscript writing, and manuscript review. Mohammad Wasay contributed to data analysis, manuscript writing, and manuscript review.

\section{Data Availability Statement}

All data is available for review. 


\section{References}

1 Anwar A, Saleem S, Aamir A, Diwan M. Organization of stroke care in Pakistan. Int J Stroke. 2020;15(5):565-6.

2 Nomani AZ, Nabi S, Badshah M, Ahmed S. Review of acute ischaemic stroke in Pakistan: progress in management and future perspectives. Stroke Vasc Neurol. 2017;2(1):30-9.

3 Malik A, Khan MA, Zehra F, Wasay M, Khan RN. Potential risk factors of stroke: a community-based, cross-sectional study from sindh province of Pakistan. Khyber Med Univ J. 2020;12(1):25-8.

4 Hashmi M, Khan M, Wasay M. Growing burden of stroke in Pakistan: a review of progress and limitations. Int J Stroke. 2013;8(7):57581.

5 Sherin A, Ul-Haq Z, Fazid S, Shah BH, Khattak MI, Nabi F. Prevalence of stroke in Pakistan: findings from Khyber Pakhtunkhwa integrated population health survey (KP-IPHS) 2016-17. Pak J Med Sci. 2020;36(7):1435.
6 Jafar TH. Blood pressure, diabetes, and increased dietary salt associated with stroke-results from a community-based study in Pakistan. J Hum Hypertens. 2006;20(1):83-5.

7 Farooq MU, Majid A, Reeves MJ, Birbeck GL. The epidemiology of stroke in Pakistan: past, present, and future. Int J Stroke. 2009;4(5): 381-9.

8 Khealani BA, Hameed B, Mapari UU. Stroke in Pakistan. J Pak Med Assoc. 2008;58(7):400.

9 Khealani BA, Javed ZF, Syed NA, Shafqat S, Wasay M. Cost of acute stroke care at a tertiary care hospital in Karachi, Pakistan. J Pak Med Assoc. 2003;53(11):552.

10 Nomani AZ, Nabi S, Badshah M, Ahmed S. Review of acute ischaemic stroke in Pakistan: progress in management and future perspectives. Stroke Vasc Neurol. 2017;2(1):30.
11 Ahmad S, Rashid U, Mansour O, Akhtar S. Acute ischemic stroke treatment barriers in Pakistan. Pakistan J Neurol Sci. 2020;15(4): 4-6.

12 Iqbal A, Haider SA, Kazmi S. Limitations to intravenous thrombolytic therapy in acute ischemic stroke in our settings. Pakistan J Med Health Sci. 2016;10(3):1047-9.

13 Sajjad Z. Neuro-imaging facilities in Pakistan. J Pak Med Assoc. 2003;53(12):621-3.

14 Wasay M. Present and future of neurology in Pakistan. Pakistan J Neurol Sci. 2016;11(1): $1-2$.

15 Mansoor SN, Rathore FA, Ikram M. Stroke rehabilitation services in pakistan: current status and future directions. Khyber Med Univ J. 2020;12(4):333-5.

16 Kamal AK, Itrat A, Naqvi I, Khan M, Channa $\mathrm{R}$, Khatri I, et al. Ischemic stroke care-official guidelines from the Pakistan society of neurology. Pakistan J Neurol Sci. 2010;51(1):38. 